\title{
PENATALAKSANAAN FISIOTERAPI PADA PENDERITA GANGGUAN NYERI AKIBAT SINDROM PIRIFORMIS DENGAN TEKNIK STRAIN COUNTERSTRAIN DAN CONTRACT RELAX STRETCHING DI KELURAHAN PEKAPURAN RAYA KOTA BANJARMASIN
}

\author{
(Management of Physiotherapy in Patients with Pain Disorders Due to \\ Piriformis Syndrome with Strain Counterstrain Technique and Contract \\ Relax Stretching in Kelurahan Pekapuran Raya of Banjarmasin City)
}

\author{
Annisa Rizky Puteri ${ }^{1}$, Nafi'ah ${ }^{1}$, Muhammad Tahdi ${ }^{1}$ \\ ${ }^{1}$ DIII Fisioterapi, Politeknik Unggulan Kalimantan \\ Email: Annisar.1309@gmail.com
}

\begin{abstract}
Continuous use of muscles can may caused hyperactively muscle activity which eventually induced pain and muscle spasm in the lower back area to the backside. In addition, muscle spasm may lead pressure on the nerves to generated swelling, inflammation, and symptoms of nerve irritation. One of the nerve irritations that often results from muscle spasm is piriformis syndrome. Piriformis syndrome is a musculoskeletal condition characterized by pain in the waist, lower back to the backside upper lower limbs that results from shortening or spasm piriformis obtained compression of the sciatic nerve. As a result of these problems, the authors conducted a study to determine the management of physiotherapy using Strain Counterstrain technique and Contract Relax Stretching in reducing pain due to Piriformis syndrome. This research was conducted in the Kelurahan Pekapuran Raya of Banjarmasin City using a case study method with a visual analog scale (VAS) and Brief Pain Inventory Questionnaire (BPI). The results of the study are Strain Counterstrain and Contract Relax Stretching for 12 times therapy in 4 weeks can reduce pain disorders in the condition of Piriformis syndrome.
\end{abstract}

\section{Keywords : Pain, Piriformis Syndrome, Strain Counterstrain, Contract Relax Stretching}

\begin{abstract}
ABSTRAK
Pemakaian otot yang dilakukan terus-menerus dapat menyebabkan otot bekerja hiperaktif yang akhirnya menimbulkan nyeri serta spasme di daerah pinggang bawah sampai bokong. Selain itu, spasme otot dapat menyebabkan tekanan pada saraf sehingga menimbulkan pembengkakan, peradangan, dan gejala iritasi saraf. Salah satu iritasi saraf yang sering terjadi akibat spasme otot adalah sindrom piriformis. Sindrom piriformis adalah kondisi muskuloskeletal yang ditandai dengan nyeri pada pinggang, punggung bawah hingga pantat dan paha yang terjadi akibat pemendekan atau spasme $m$. piriformis sehingga menghasilkan kompresi terhadap nervus sciatic. Akibat problematika tersebut, maka penulis melakukan penelitian untuk mengetahui penatalaksanaan fisioterapi menggunakan teknik Strain Counterstrain dan Contract Relax Stretching dalam menurunkan nyeri akibat sindrom piriformis. Penelitian ini dilakukan di Kelurahan Pekapuran Raya Kota Banjarmasin menggunakan metode case study dengan alat ukur visual analog scale (VAS) dan Brief Pain Inventory Questionnaire (BPI). Dari hasil penelitian didapatkan Strain Counterstrain dan
\end{abstract}


Contract Relax Stretching selama 12 kali terapi dalam waktu 4 minggu dapat menurunkan gangguan nyeri pada kondisi sindrom piriformis.

\section{Kata kunci : Nyeri, Sindrom Piriformis, Strain Counterstrain, Contract Relax Stretching}

\section{PENDAHULUAN}

Pemakaian otot yang dilakukan terus-menerus dapat menyebabkan otot bekerja hiperaktif yang akhirnya menimbulkan nyeri serta spasme didaerah pinggang bawah sampai bokong. Selain itu, spasme otot dapat menyebabkan tekanan pada saraf sehingga menimbulkan pembengkakan, peradangan, dan gejala iritasi saraf. Salah satu iritasi saraf yang sering terjadi akibat spasme otot adalah sindrom piriformis (Ebraheim et al, 2017). Sindrom piriformis adalah kondisi muskuloskeletal yang ditandai dengan nyeri pada pinggang, punggung bawah hingga pantat dan paha yang terjadi akibat pemendekan atau spasme $m$. piriformis sehingga menghasilkan kompresi terhadap nervus sciatic (Tonley, et al., 2010)

Penentuan prevalensi sindrom piriformis masih menemui kesulitan karena sindrom ini seringkali didiagnosis sebagai penyakit lain. Sindrom piriformis lebih sering terjadi pada wanita daripada pria, hal ini diakibatkan oleh faktor biomekanik terkait dengan sudut $\mathrm{m}$. quadriceps femoris ( $Q$ angle) wanita yang lebih luas. Di Amerika Serikat, rasio insiden wanita dan pria dari sindrom piriformis adalah 6:1 (Shah et al, 2017). Di India, pada September 2010-Agustus 2012 Terdapat 6,25\% (182 dari 2.910) yang didiagnosa sindrom piriformis dari pasien rawat jalan dengan rentang usia 15-81 tahun yang mengalami keluhan nyeri punggung bawah/bokong dengan Ischialgia . (Singh et al, 2013).

Di Indonesia, tepatnya di RS. Wahidin Sudirohusodo Makassar menurut hasil observasi oleh Risal pada bulan April 2010 dengan data dari bulan Januari- Maret 2010 terdapat 6,9\% (46 dari 666 pasien) yang berkunjung mengalami penyakit Sindrom piriformis. Di Banjarmasin, berdasarkan data pasien rekam medis poli fisioterapi RS. Dr. Moch. Ansari pada bulan Desember 2017 sampai bulan November 2018 Saleh terdapat 3,2\% (6 dari 152 pasien) dengan Ichialgia ditemukan memiliki sindrom piriformis.

Berdasarkan penelitian, diketahui bahwa sindrom piriformis dapat ditangani dengan Strain Counterstrain (SCS) dan Contract Relax Stretching (CRS). Hal ini dibuktikan oleh Risal (2010) yang meneliti bahwa teknik Strain Counterstrain (SCS) efektif dalam mengurangi nyeri. Selain itu, Fata (2016) juga menyebutkan bahwa teknik Strain Counterstrain (SCS) pada stretching dapat menurunkan nyeri akibat sindrom piriformis. Strain Counterstrain (SCS) dapat memberikan manfaat melalui pengaturan kembali secara otomatis pada muscle spindle, yang dapat membantu melaporkan panjang dan tonus otot. Adapun Contract Relax Stretching (CRS) pada otot piriformis menurut Sugijanto (2009) dalam Risal (2010) menyatakan bahwa teknik Contract Relax Stretching (CRS) efektif digunakan untuk mengatasi problematik spasme (tightness) pada otot. Selain itu, Risal (2009) dalam Fata (2016) juga membuktikan bahwa Contract Relax Stretching (CRS) dapat menurunkan nyeri pada penderita sindrom piriformis. Namun teknik SCS dan CRS belum pernah digunakan dalam menangani kasus sindrom piriformis di Kalimantan Selatan. Atas hal ini, peneliti tertarik untuk melakukan penelitian dengan judul "Penatalaksanaan Fisioterapi pada Penderita Gangguan Nyeri Akibat Sindrom Piriformis dengan Teknik Strain Counterstrain dan Contract Relax Streatching di Kelurahan Pekapuran Raya Kota Banjarmasin". 


\section{METODE PENELITIAN Jenis Penelitian}

Jenis penelitian ini menggunakan studi kasus (case study) menggunakan satu sampel yang menderita piriformis dengan frekuensi 3 kali seminggu selama satu bulan.

\section{Waktu dan Tempat}

Penelitian dilaksanakan pada tanggal 15 April - 10 Mei 2019 di Jalan Pangeran Antasari No. 3 RT. 5 RW. 1 Kelurahan Pekapuran Raya Kecamatan Banjarmasin Timur Kota Banjarmasin Provinsi Kalimantan Selatan.

\section{Prosedur Pengambilan Data}

Pengambilan data penelitian dilaksanakan melalui dua cara yaitu data dengan primer dan data sekunder di Kelurahan Pekapuran Raya Kota Banjarmasin. Data primer diperoleh dari hasil pemeriksaan dan pengukuran langsung pada pasien yang dijadikan sampel kasus menggunakan instrumen penelitian yaitu Visual Analog Scale (VAS) dan Brief Pain Inventory (BPI) Questionnaire. Sedangkan data sekunder diperoleh dengan melihat status medical record atau hasil pemeriksaan lainnya yang mendukung (foto rontgen, CT-Scan, MRI).

\section{Analisis Pengolahan Data}

Dua tahapan dalam pengolahan data yang dilakukan, yaitu editing dan tabulating

\section{Analisis Data}

Data yang terkumpul adalah data hasil dari pengukuran intensitas nyeri pada kasus Sindrom piriformis melalui Visual Analog Scale (VAS) dan Brief Pain Inventori Questionaire (BPI) dengan modalitas fisioterapi berupa Strain Counterstrain (SCS) dan Contract Relax Stretching (CRS). Kemudian setelah diberikan intervensi fisioterapi, data yang dipeoleh melalui VAS dan BPI akan dilihat perkembangannya. Berdasarkan data tersebut dapat dilihat mengenai pengaruh pemberian modalitas fisioterapi tersebut pada kasus sindrom piriformis dengan gangguan nyeri.

\section{HASIL DAN PEMBAHASAN}

\section{Hasil}

Setelah dilakukan assessment fisioterapi dan pada pasien atas nama Tn. Y usia 70 tahun dengan kondisi gangguan nyeri akibat sindrom piriformis didapatkan problematik fisioterapi adanya nyeri tekan pada $m$. piriformis dan nyeri gerak pada hip joint, adanya nyeri menjalar dan parastesia dari pantat dekstra hingga area $m$. hamstring dan adanya spasme pada $m$. piriformis dextra, $m$ hamstring dextra serta $m$. gastrocnemeus dextra. kemudian dilakukan pengukuran nyeri sebelum dan sesudah intervensi menggunakan VAS dan menggunakan BPI setiap seminggu sekali sehingga didapatkan hasil pengukuran yang diperlihatkan pada gambar 1 dan gambar 2 . 


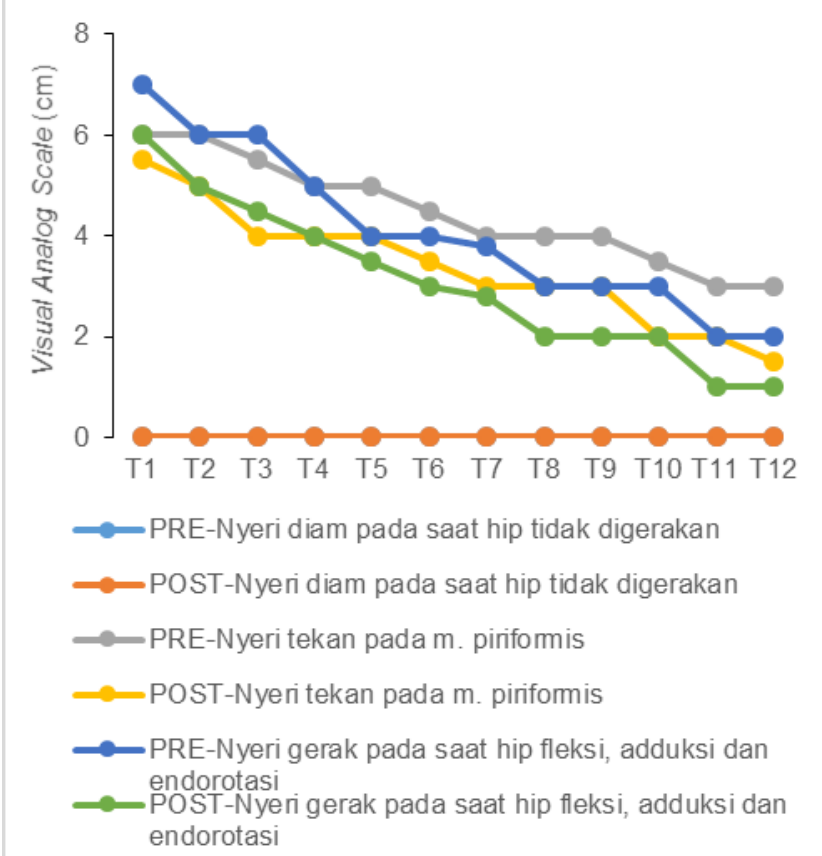

Gambar 1. Grafik Hasil Evaluasi Nyeri Menggunakan VAS

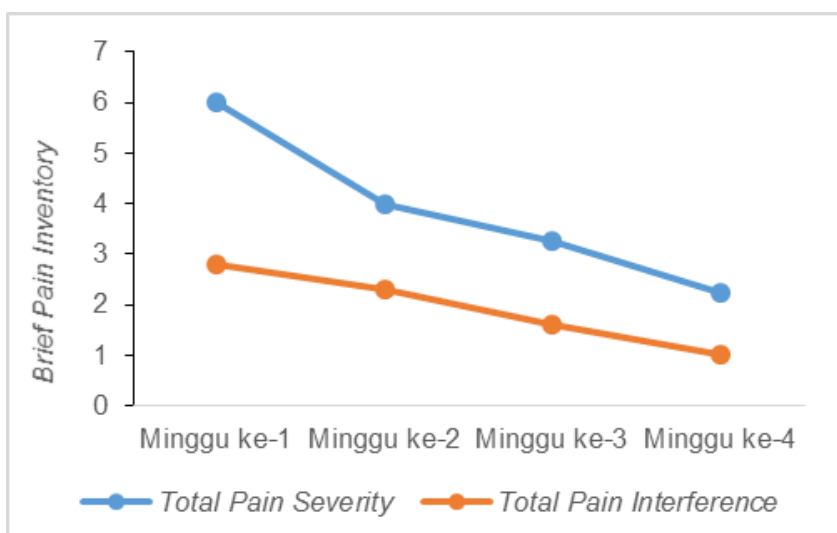

Gambar 2. Grafik Hasil Evaluasi Nyeri Menggunakan BPI

Berdasarkan gambar 1 telah diperlihatkan grafik hasil penurunan nyeri yang dirasakan pasien yang diukur menggunakan Visual Analog Scale (VAS) dan didapatkan hasil nilai VAS nyeri tekan sebelum diberikan intervensi pada $T 1$ adalah sebesar $6 \mathrm{~cm}$ dan setelah intervensi terjadi penurunan nyeri menjadi $5,5 \mathrm{~cm}$. Kemudian setelah diberikan 12 kali terapi dalam 4 minggu didapatkan penurunan nyeri tekan yang signifikan yaitu $1,5 \mathrm{~cm}$. Selain itu, penurunan nyeri juga terjadi pada nyeri gerak yang sebelum diberikan intervensi sebesar 7 $\mathrm{cm}$ dan setelah diberikan intervensi nilainya menjadi $6 \mathrm{~cm}$. Kemudian pada terapi terakhir didapatkan penurunan nyeri gerak yang signifikan menjadi $1 \mathrm{~cm}$.

Pada gambar 2 diperlihatkan grafik penurunan nyeri yang diukur menggunakan Brief Pain Invetory Questionaire (BPI). Pada minggu pertama nilai Total Pain Severity atau nilai total buruknya nyeri adalah 6 setelah diberikan intervensi selama 4 minggu didapatkan hasil pada minggu ke-empat menjadi 2,25. Sedangkan pada nilai Total Pain Interference atau nilai total gangguan nyeri terhadap aktivitas pada minggu pertama sebesar 2,8 dan setelah diberikan intervensi selama 4 minggu didapatkan hasil pada minggu ke-empat menjadi 1. 


\section{Pembahasan}

Berdasarkan hasil data di atas memberikan bukti klinis bahwa pemberian modalitas terapi berupa Strain Counterstrain (SCS) dan Contract Relax Stretching (CRS) yang diberikan selama 12 kali dalam 4 minggu efektif dalam menurunkan nyeri pada pasien Tn. Y yang mengalami sindrom piriformis.

Penelitian ini sejalan dengan penelitian yang dilakukan oleh Perreault (2009) menunjukan bahwa Strain Counterstrain (SCS) dapat mengurangi nyeri tekan pada $\mathrm{m}$. upper trapezius. Selain itu, penelitian yang dilakukan oleh Ibanez-Garcia (2009) menunjukan bahwa Strain Counterstrain (SCS) selama 3 minggu berturut-turut dapat mengurangi nyeri akibat trigger point pada $\mathrm{m}$. masseter yang dialami oleh 25 partisipan. Studi lain yang dilakukan oleh Risal (2010) pada 10 orang partisipan yang mengalami nyeri akibat sindrom piriformis diberikan Strain Counterstrain (SCS) sebanyak 12 kali selama 6 minggu didapatkan hasil adanya penurunan nyeri yang diukur dengan visual analog scale (VAS).

Berdasarkan hasil penelitian di atas, nyeri dapat berkurang dikarenakan Strain Counterstrain (SCS) dapat menyebabkan stimulasi pada muscle spindle otot yang mengalami spasme sehingga menghasilkan aktivasi proprioseptor yang mempersarafi muscle spindle. Aktivitas proprioseptor akan menginhibisi impuls nosisensorik yang sebelumnya aktif karena adanya patologi spasme/tightness. Disamping itu, rangsangan terhadap muscle spindle menyebabkan terjadinya relaksasi secara refleks pada otot yang spasme. Kemudian, teknik ischemic compression pada lokasi tender point otot piriformis dapat menghasilkan aliran sirkulasi yang meningkat setelah kompresi dilepas. Disamping itu, tekanan yang menetap pada tender point tersebut dapat menghasilkan hambatan impuls nosisensorik sehingga saat kompresi dilepaskan timbul rasa nyaman (nyeri berkurang) setelah beberapa menit (Chaitow, 2003 dalam Risal, 2010).

Modalitas lain yang dipilih adalah exercise selain strain Counterstrain (SCS). Exercise efektif mengurangi nyeri dikarenakan exercise dapat mengaktifkan opioid endogen yang dilepaskan dan diatur oleh otak sehingga akan terjadi mekanisme penghambatan nosiseptif dari supraspinal dan kemudian akan menimbulkan efek analgesik (Fuentes et al, 2011).

Contract Relax Stretching (CRS) merupakan salah satu teknik Proprioceptive Neuromuscular Facilitation (PNF) yang bertujuan untuk menurunkan nyeri. Penelitian yang dilakukan oleh Maruli et al (2013) menujukan bahwa Contract Relax Stretching (CRS) sebanyak 3 kali seminggu selama 1 bulan efektif dalam menurunkan nyeri akibat sindrom myofascial pada otot $m$. upper trapezius yang dialami oleh 11 orang partisipan. Selain itu, penelitian yang dilakukan oleh Pratama (2013) juga menunjukan adanya penurunan nyeri akibat sindrom myofascial trigger point pada otot $m$. upper trapezius setelah diberikan Contract Relax Stretching (CRS) pada 7 partisipan selama 15 hari. Dan dalam penelitian yang dilakukan oleh Risal (2010) pada 10 orang partisipan yang mengalami nyeri akibat sindrom piriformis diberikan Contract Relax Stretching (CRS) sebanyak 12 kali selama 6 minggu didapatkan hasil adanya penurunan nyeri yang diukur dengan visual analg scale (VAS).

Penurunan nyeri yang terjadi berdasarkan beberapa penelitian di atas dikarenakan Contract Relax Stretching (CRS) memiliki efek autogenic inhibisi yang dapat menyebabkan otot mengalami relaksasi. Kontraksi yang maksimal dari otot yang spasme/tightness diikuti dengan relaksasi pasca kontraksi akan menghasilkan respon autogenic inhibisi sehingga otot yang spasme/tightness dapat mencapai relaksasi sempurna. Adanya kontraksi otot yang kuat kemudian relaksasi dari otot tersebut akan mengakibatkan vasodilatasi pembuluh darah dan akan mempermudah mekanisme pumping action sehingga proses metabolisme dan sirkulasi lokal lebih lancar, akibatnya proses pengangkutan sisa-sisa metabolisme $(P$ substance) dan asetabolic yang diproduksi melalui proses inflamasi dapat berjalan dengan lancar sehingga rasa nyeri dapat berkurang. (Risal, 2010; Pratama, 2013). Selain itu kontraksi otot juga memicu pelepasan $\beta$-endorfin dari hipofisis dan hipotalamus yang selanjutnya akan berikatan dengan reseptor opioid- $\mu$ sehingga menimbulkan efek analgesik di dalam tubuh dengan cara menghalangi pembentukan rangsang dalam reseptor nyeri, 
saraf sensoris, dan sistem saraf pusat sehingga akan terjadi penurunan nyeri (Nijs et al, 2012).

Berdasarkan fakta diatas, dapat memberikan bukti bahwa kedua modalitas tersebut dapat digunakan untuk menurunkan nyeri. Namun, penelitian ini juga dipengaruhi oleh beberapa faktor yang menjadi pendorong. Faktor-faktor yang menjadi pendorong keberhasilan terapi yang dilaksanakan berasal dari faktor terapis, pemilihan modalitas, serta dari pasien sendiri.

Faktor dari fisioterapis antara lain tingkat pengetahuan tentang sindrom piriformis, yang meliputi proses patologis sampai penatalaksanaan terapi, kemampuan terapis dalam memilih dan melaksanakan program terapi edukasi yang jelas dan benar kepada pasien. Modalitas fisioterapi yang digunakan tentunya akan meningkatkan tingkat keberhasilan sesuai program terapi. Sedangkan dari pasien sendiri, dukungan pasien terhadadap program terapi yang telah ditetapkan sehingga mampu memberikan hasil sesuai yang diharapkan, motivasi pasien untuk sembuh cukup tinggi, pasien juga selalu siap sedia menerima kehadiran terapis sesuai program yang dijadwalkan yaitu 12 kali dalam 4 minggu.

\section{KESIMPULAN}

Penatalaksanaan fisioterapi menggunakan teknik Strain Counterstrain (SCS) dan Contract Relax Stretching (CRS) dapat mengurangi nyeri.

\section{DAFTAR PUSTAKA}

Aras, D., Ahmad, H., \& Ahmad, A. (2016). The New Concept of Test and Measurement in Patient Care Physiotherapy. Makassar: PhysioCare Publishing.

Ebraheim, N., Andrews, K., Stirling, B., \& Tanios, M. (2017). Piriformis Syndrome or True Sciatica: Are They the Same or Different? MOJ Orthop Rheumatol, 9(3), 00357.

Fata, A. S. (2016). Pengaruh Penambahan Strain counter Strain (SCS) pada Micro Wave Diathermy (MWD) dan Stretching Terhadap Penurunan Nyeri pada Kasus Piriformis Syndrome. Skripsi. Surakarta: Universitas Muhammadiyah Surakarta.

Fuentes, J. P., Armijo-Olivo, S., Magee, D. J., \& Gross, D. P. (2011). Effects of Exercise Therapy on Endogenous Pain-relieving Peptides in Musculoskeletal Pain A Systematic Review. Clin J Pain, Volume 27 (4).

Ibanez-Garcıa, J., Alburquerque-Sendın, r., CleofasRodrıguez-Blanco, \& Girao, D. (2009). Changes in masseter muscle trigger points following strain-counterstrain or neuromuscular technique. Journal of Bodywork and Movement Therapies, 2-10.

Maruli, W. O., Sutjana, I. D., \& Indrayani, \&. A. (2013). Perbandingan Myofascial Release Technique Dengan Contract Relax Stretching Terhadap Penurunan Nyeri Pada Sindrom Myofascial Otot Upper Trapezius. Skripsi. Bali: Universitas Udayana.

Nijs, J., Kosek, E., Oosterwijck, J. V., \& Meeus, \&. M. (2012). Dysfunctional Endogenous Analgesia During Exercise in Patients with Chronic Pain: To Exercise or Not to Exercise? Pain Physician, 15:ES205-ES213.

Perreault, A., Kelln, B., Hertel, J., Pugh, K., \& Saliba, S. (2009). Short-term effects of strain counterstrain in reducing pain in upper trapezius tender points. Athletic Training and Sports Health Care, 1(5):214-21.

Pratama, G. R. (2013). Pengaruh Latihan Contract Relax Stretching Terhadap Penurunan Nyeri Myofascial Trigger Point Syndrome Otot Upper Trapezius pada Pembatik Tulis Halus Laweyan. Skripsi. Surakarta: Universitas Muhammadiyah Surakarta.

Risal. (2010). Beda Pengaruh Contract Relax Stretching Dengan Strain-Counterstrain Technique Terhadap Penurunan Nyeri pada Penderita Sindrome Piriformis di RSUP. Dr. Wahidin Sudirohusodo. Skripsi. Makassar: Jurnal Fisioterapi Makassar.

RSUD Dr Moch Ansari Saleh (2019). Data Kunjungan Pasien Fisioterapi, Poli Fisioterapi RSUD Dr Moch Ansari Saleh Banjarmasin 
Shah, S., Wang, T. W., Talavera, F., \& White, R. D. (2018, Desember 21). Medscape. Diambil kembali dari emedicine: https://emedicine.medscape.com/article/87545overview diakses pada 4 Maret 2019

Singh, U., Meena, R., Singh, C., Singh, A., Singh, A., \& Langshong, R. (2013). Prevalence of piriformis syndrome among the cases of low back/buttock pain with sciatica: A prospective study. Journal of Medical Society, 27(2), 94-99.

Tonley, J., Yun, S., Kochevar, R., Dye, J., Farrokhi, S., \& Powers, C. (2010). Treatment of an Individual with Piriformis Syndrome Focusing on Hip Muscle Strengthening and Movement Reeducation. Journal of orthopaedic \& sports physical therapy, 40(2), 103111. 